\section{Takayasu arteritis with an initial presentation of chronic monoarthritis mimicking oligoarticular juvenile idiopathic arthritis}

\author{
Maynart Sukharomana, ${ }^{1}$ \\ Sorawit Viravan, 2 \\ Nuntawan Piyaphanee, ${ }^{3}$ \\ Sirirat Charuvanij ${ }^{1}$
}

1Division of Rheumatology; 2Division of Neurology; 3Division of Nephrology, Department of Pediatrics, Faculty of Medicine, Siriraj Hospital, Mahidol University, Bangkok, Thailand

\begin{abstract}
Patients with Takayasu arteritis (TA) generally present with non-specific symptoms that, if unrecognized and untreated, may develop vessel stenosis and/or aneurysm. There is limited data regarding chronic monoarthritis as the initial presentation in children with TA. We report a 6-yearold girl diagnosed and treated as oligoarticular juvenile idiopathic arthritis (JIA). She later developed stroke with malignant hypertension and was definitively diagnosed with TA. She additionally developed proteinuria secondary to focal segmental glomerulosclerosis. This is the report of a patient with chronic monoarthritis mimicking oligoarticular JIA which chronic monoarthritis was the presentation of TA. Since JIA is a diagnosis of exclusion, any atypical features of oligoarticular JIA should illuminate the possibility of an alternative diagnosis. Our literature review focused on musculoskeletal presentations of children with TA.
\end{abstract}

\section{Introduction}

Patients with Takayasu arteritis (TA) generally initially present with non-specific symptoms such as fever, weight loss, myalgia, and arthralgia that, if unrecognized and untreated, may develop vessel stenosis and/or aneurysm. There is currently limited data available regarding chronic monoarthritis as the initial presentation in children with TA.1-12 Here, we report a 6year-old girl with chronic monoarthritis mimicking oligoarticular juvenile idiopathic arthritis (JIA) prior to being definitively diagnosed with TA.

\section{Case Report}

The patient is a previously healthy 6year-old Thai girl. She was referred to our tertiary referral center at the age of 5 years with right knee pain, swelling, and limping for 6 months. Pain usually developed in the morning, and partial relief was obtained with nonsteroidal anti-inflammatory drugs. There was no presence of fever or constitutional symptoms, and the review of systems was unremarkable. There was no history of contact with any persons having tuberculosis (TB). There was no family history of autoimmune diseases, cerebrovascular events, or aneurysms. Her vitals were: blood pressure, 113/83 $\mathrm{mmHg}$; pulse rate, 94/minute; respiratory rate, $20 /$ minute; and temperature, $37.1^{\circ} \mathrm{C}$. Physical examination was unremarkable, except for mild pallor and dental carries. On musculoskeletal examination, she had moderately swollen, warm, tender, pain on motions without limited range of motions of the right knee.

Complete blood count showed hemoglobin $9.5 \mathrm{~g} / \mathrm{dl}$, white blood cells 12,500 cells $/ \mathrm{mm}^{3}$ (neutrophils $55.2 \%$, lymphocytes $34.6 \%$ ), and platelets 694,000 cells $/ \mathrm{mm}^{3}$. Erythrocyte sedimentation rate (ESR) and c-reactive protein (CRP) were $73 \mathrm{~mm} / \mathrm{hr}$ and $48 \mathrm{mg} / \mathrm{L}$, respectively. Blood chemistry was unremarkable. Urinalysis was normal. Antinuclear antibody (ANA) was borderline and rheumatoid factor (RF) was negative. Plain radiograph of the right knee revealed joint effusion without osteolytic lesion. Slit-lamp examination showed no uveitis. Purified protein derivative (PPD) skin test was negative and chest $\mathrm{x}$-ray was normal. Synovial fluid analysis revealed yellow color, nucleated cells $3800 / \mathrm{mm}^{3}$ (neutrophil 38\%, lymphocyte 60\%) with negative Gram's stain, 16s ribosome, and PCR for TB. Bacterial and Mycobacterial culture showed no growth for any organisms. The provisional diagnosis at that point was oligoarticular JIA, and the patient was treated with ibuprofen $40 \mathrm{mg} / \mathrm{kg} /$ day on a regular basis. The patient's symptoms improved initially, but she later developed arthritis flare at the same knee at 5 months and 10 months. Intra-articular steroid injection with triamcinolone acetonide was performed. Her arthritis improved with intraarticular steroid injections.

At the age of 6 years, the patient developed sudden weakness of the left arm, left leg, and left face lasting for 10 minutes. The same set of symptoms then redeveloped 20 minutes later. In the emergency room, vital signs showed elevated blood pressure $(185 / 131 \mathrm{mmHg})$, pulse rate $126 /$ minute, respiratory rate $22 /$ minute, and temperature
Correspondence: Sirirat Charuvanij, Division of Rheumatology, Department of Pediatrics, Faculty of Medicine, Siriraj Hospital, Mahidol University, 2 Wanglang Road, Bangkoknoi, Bangkok 10700, Thailand.

Tel.: +66.2.419.5655 - Fax: +66.2.419.5960.

E-mail: sirirat.chv@mahidol.ac.th

Key words: Takayasu arteritis, oligoarticular juvenile idiopathic arthritis, focal segmental glomerulosclerosis, hypertension, stroke.

Acknowledgements: the authors gratefully acknowledge the patient profiled in this study and her parents for permitting them to report details relating to her case. The authors would also like to thank Associate Professor Boonyarit Cheunsuchon, MD for the pathology report and image of the renal biopsy taken from this patient.

Contributions: MS and SC drafted the manuscript. SV, NP, and SC contributed to the writing and reviewing of the manuscript. All authors read and approved the final manuscript.

Conflict of interest: the authors declare no potential conflict of interest.

Funding: none.

Received for publication: 20 February 2018. Accepted for publication: 27 June 2018

This work is licensed under a Creative Commons Attribution NonCommercial 4.0 License (CC BY-NC 4.0).

(C) Copyright M. Sukharomana et al., 2018

Licensee PAGEPress, Italy

Pediatric Reports 2018; 10:7648

doi:10.4081/pr.2018.7648

$36.6{ }^{\circ} \mathrm{C}$. Neurological examination showed full Glasgow Coma Score $\left(\mathrm{E}_{4} \mathrm{~V}_{5} \mathrm{M}_{6}\right.$, spontaneous eye opening, verbal response with orientation, and motor response being able to obey commands); pupils $3 \mathrm{~mm}$, with both reactive to light; left hemiparesis (motor power grade IV at left arm and left leg); and, decreased left nasolabial fold. There was audible bruit over the left carotid artery and pulse deficit at the right radial artery. Blood pressure was repeated in all extremities, showing hypertension and discrepancy of more than $10 \mathrm{mmHg}$ between the 2 upper and 2 lower extremities (right arm 151/121, left arm 179/137, right leg 154/103, left leg 173/116 $\mathrm{mmHg}$ ). Magnetic resonance imaging of the brain showed restricted diffusion at right basal ganglia.

Based on clinical features that included stroke, hypertension, carotid bruit, and pulse deficit, she was suspected of having TA. Computed tomography angiography (CTA) of the brain with carotid and subse- 
quent magnetic resonance angiography (MRA) of the brain, both showed total occlusion of the brachiocephalic trunk, and saccular aneurysm (sized $2.1 \times 1.4 \mathrm{~cm}$ ) of the aortic arch involving the origin of the brachiocephalic trunk, the left common carotid artery, and the left subclavian artery (Figure 1A). CTA of the thoracoabdominal aorta showed suprarenal abdominal aortic saccular aneurysm (sized $5.5 \times 3.8 \times 4.5 \mathrm{~cm}$ ); occlusion at the origin of the celiac trunk, the superior mesenteric artery, and the right renal artery; and, luminal narrowing of right external iliac artery (Figure 1B). The patient fulfilled the EULAR/PReS (European League Against Rheumatism/Paediatric Rheumatology European Society) classification criteria for TA. 13

During the hospital course, she developed nephrotic range proteinuria, as demonstrated by spot urine protein to creatinine ratio of $5.8 \mathrm{mg} / \mathrm{mg}$ creatinine and protein excretion of $70 \mathrm{mg} / \mathrm{m}^{2} / \mathrm{hr}$ in 24-hour urine sample. Renal biopsy of the left kidney revealed segmental sclerosis with marked podocyte hyperplasia, no increase in cells or matrix in the mesangium, no capillary wall thickening, and no crescents or endocapillary proliferation. Tubules and interstitium showed no tubular atrophy, interstitial fibrosis, or interstitial mononuclear infiltration. The arterioles showed mild hyalinosis. There was no vasculitis. Immunofluorescence study was negative for staining of all immunoglobulins, C3, C1q, kappa, lambda, and fibrinogen. All findings were compatible with focal segmental glomerulosclerosis (FSGS) (Figure 2).

The patient received intravenous pulse methylprednisolone $30 \mathrm{mg} / \mathrm{kg} /$ day for 3 consecutive days, followed by oral prednisolone $2 \mathrm{mg} / \mathrm{kg} /$ day and aspirin 5.4 $\mathrm{mg} / \mathrm{kg} /$ day. She was able to recover all functions. Motor power was fully gained within 3 days after the onset of stroke. Intravenous cyclophosphamide (500-750 $\mathrm{mg} / \mathrm{m}^{2} /$ dose) was administrated every 4 weeks for 6 months. Her blood pressure was controlled by atenolol and amlodipine. For prophylaxis against Pneumocystis jirovecii, she was given cotrimoxazole with 5 $\mathrm{mg} / \mathrm{kg} /$ day of trimethoprim three days per week. After completing the $6^{\text {th }}$ course of intravenous cyclophosphamide, she underwent surgery. Histopathology revealed neutrophils and eosinophils infiltration at the vessel wall.

\section{Discussion}

In the present study, we report the 6year-old girl who initially was diagnosed as oligoarticular JIA, and later being defini- tively diagnosed with TA. This study is the report of the patient with chronic monoarthritis mimicking oligoarticular JIA as the presentation of TA. There is currently limited data regarding JIA and TA. Rossor E reported an 8-year-old girl who presented with fever and limb pain initially diagnosed as systemic juvenile chronic arthritis, but was later diagnosed as TA. Her limb pain was apparently a symptom of intermittent

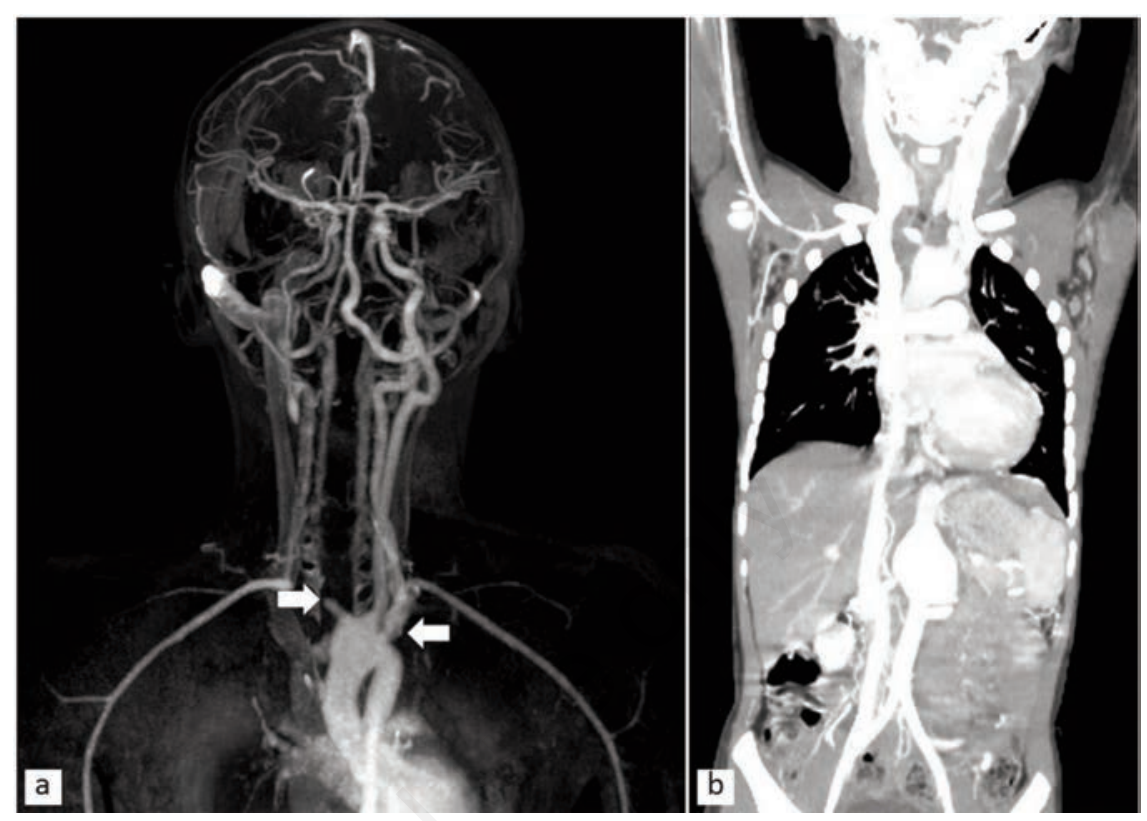

Figure 1. A) Magnetic resonance angiography of the brain and carotid arteries showed total occlusion of the brachiocephalic trunk (white arrow to the right), and saccular aneurysm $(2.1 \times 1.4 \mathrm{~cm})$ of the aortic arch involving the origin of brachiocephalic trunk, the left common carotid artery, and the left subclavian artery (white arrow to the left); B) Computed tomography angiography thoracoabdominal aorta showed suprarenal abdominal aortic saccular aneurysm sized $5.5 \times 3.8 \times 4.5 \mathrm{~cm}$.

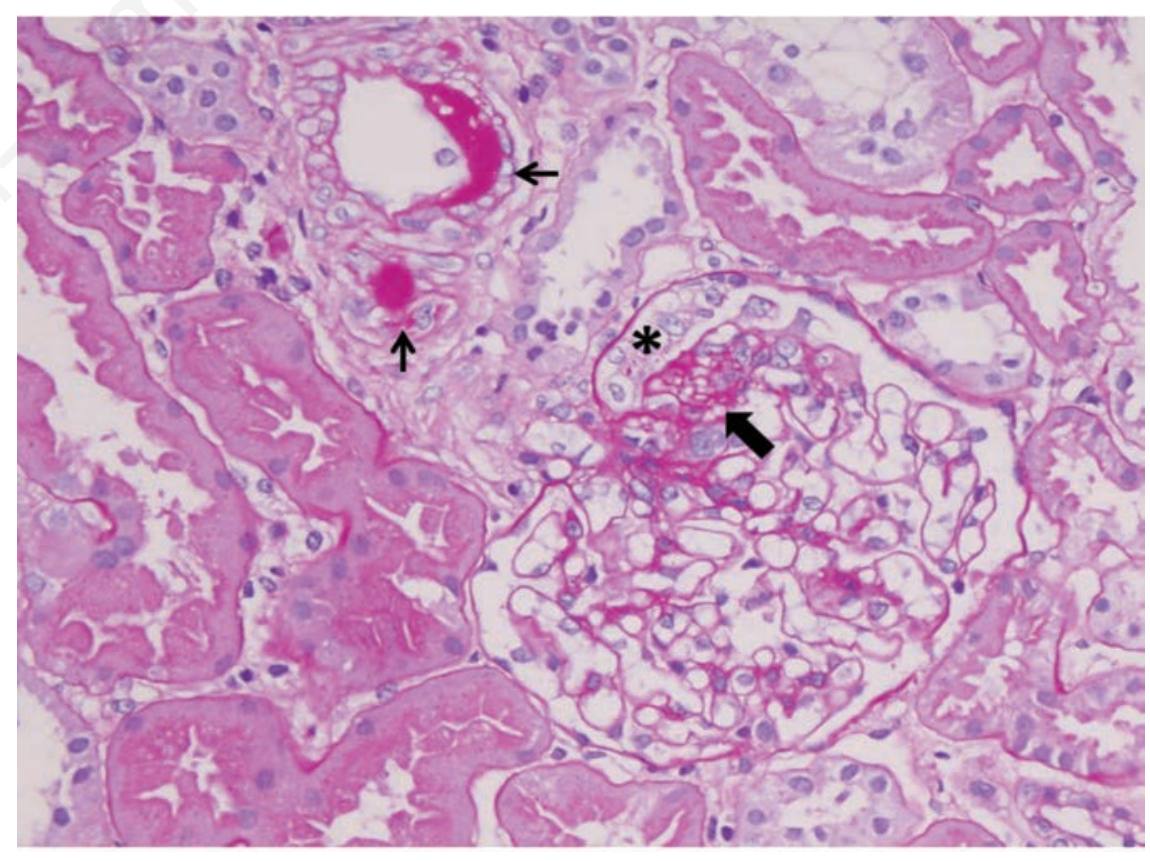

Figure 2. Renal pathology was compatible with focal segmental glomerulosclerosis. Renal histology (PAS stain) revealed an affected glomerulus showing segmental sclerosis (big black arrow) with podocyte hyperplasia $(*)$, and an arteriole with hyalinosis (small black arrows). 
claudication that was associated with walking, not true arthritis. ${ }^{1}$ A case report by Hall et al. ${ }^{2}$ described a female patient with onset of polyarticular juvenile rheumatoid arthritis (JRA) at age 7 that presented with small and large joints arthritis with negative ANA and RF. She returned at age 17 years with an additional complaint of fatigue at both forearms after prolonged use. At this visit, physical examination showed not only widespread arthritis but also undetectable blood pressure at both arms and multiple audible bruits. This patient was diagnosed as TA 12 years after the initial presentation of polyarthritis. ${ }^{2}$ Case series in pediatric TA with clinical presentation of musculoskeletal manifestations have been reported. ${ }^{3-12}$ In one of those series, Hahn D, et al, reported a child having arthralgia for 2 years and was previously diagnosed as JRA prior to the diagnosis of TA. 5 The phenotypes and per- centage of patients having musculoskeletal symptoms varied in the reviewed studies ranging from $1.4 \%$ to $65.4 \%$. This discrepancy could be due to some missing data relating to the retrospective study design (Table 1). 3-12

From our literature review of TA in children with initial musculoskeletal manifestations, there were variations regarding TB status; PPD positivity ranged from 15.8 to $90.3 \% 0^{3-7,9,11}$ and TB disease was present in 0 to $25 \%$ (Table 1).4-7,9,11,12 Although there is an association of TB and TA which could be explained by the TB infection or the cross reactivity, whether the TB status was associated with musculoskeletal manifestions cannot be concluded.

From the diagnostic challenges during the early course of disease in this patient, it seems interesting whether chronic monoarthritis was the manifestation of TA. Given the elevated ESR and CRP, these results could be secondary to systemic vasculitis rather than oligoarticular JIA. The large aneurysm found in the patient could reflect its chronicity, indicating that it may have taken months to develop. Additionally, when retrospectively reviewed, the patient had intermittently elevated blood pressure in the range of $110-128 / 71-89 \mathrm{mmHg}$ during follow-up visits prior to the onset of stroke. Taken together, it is likely that the patient had TA at the time of JIA diagnosis.

Another compelling finding in this case is that the patient developed nephrotic range proteinuria with biopsy-proven FSGS. Glomerular disease associated with TA is uncommon. Very few studies have reported glomerulopathy, such as membranous nephropathy and FSGS, in adults. ${ }^{14,15}$ Data describing association between FSGS and TA in children is scarce. From a case series

Table 1. Studies in pediatric patients diagnosed as Takayasu arteritis with initial musculoskeletal presentations.

\begin{tabular}{|c|c|c|c|c|c|c|c|c|c|}
\hline $\begin{array}{l}\text { Author } \\
\text { and year }\end{array}$ & Country & $\begin{array}{l}\text { Musculokeletal } \\
\text { presentations }\end{array}$ & $\begin{array}{l}\text { Number of cases/ } \\
\text { Total cases }\end{array}$ & $\begin{array}{l}\text { Percentage } \\
(\%) \\
\text { as JIA }\end{array}$ & $\begin{array}{l}\text { Initially } \\
\text { diagnosed }\end{array}$ & $\begin{array}{l}\text { ESR } \\
(\mathrm{mm} / \mathrm{hr})\end{array}$ & $\begin{array}{l}\text { CRP } \\
(\mathrm{mg} / \mathrm{L})\end{array}$ & $\begin{array}{l}\text { TB } \\
\text { PPD } \\
\text { positivity } \\
(\%)\end{array}$ & $\begin{array}{l}\text { tatus } \\
\text { TB } \\
\text { disease } \\
(\%)\end{array}$ \\
\hline \multicolumn{10}{|l|}{ Case series } \\
\hline Morales $1991^{3}$ & Mexico & $\begin{array}{l}\text { Arthritis } \\
\text { or history of arthritis, } \\
\text { pauciarticular, primarily } \\
\text { large joints }\end{array}$ & 17/26 & 65.4 & No & $>50$ in $85 \%$ & $>3+$ in $81 \%$ & 73 & N/A \\
\hline Hong 19924 & Korea & $\begin{array}{l}\text { Lower extremity pain } \\
\text { Joint pain }\end{array}$ & $\begin{array}{l}1 / 70 \\
1 / 70\end{array}$ & $\begin{array}{l}1.4 \\
1.4\end{array}$ & $\begin{array}{l}\text { No } \\
\text { No }\end{array}$ & $\geq 20$ in $56 \%$ & N/A & 90.3 & 12.9 \\
\hline Hahn $1998^{5}$ & $\begin{array}{l}\text { South } \\
\text { Africa }\end{array}$ & Arthralgia & $2 / 31$ & 6.4 & $\begin{array}{l}\text { Yes } \\
\text { JRA in } 1 \text { case }\end{array}$ & \multicolumn{2}{|c|}{ Elevated ESR or CRP in $74.1 \%$} & 87.0 & 12.9 \\
\hline Jain 20006 & India & Arthralgia & $1 / 24$ & 4.1 & No & $\geq 20$ in $41.7 \%$ & $\mathrm{~N} / \mathrm{A}$ & 29.1 & $\mathrm{~N} / \mathrm{A}$ \\
\hline Muranjan 20007 & India & Arthralgia & $1 / 17$ & 5.8 & No & N/A & N/A & 35.2 & 0 \\
\hline Fieldston $2003^{8}$ & USA & Arthralgia & $3 / 6$ & 50.0 & No & $\begin{array}{l}\text { Mean 99, } \\
\text { Range 73-125 }\end{array}$ & N/A & N/A & N/A \\
\hline Cakar $2008^{9}$ & Turkey & Arthralgia/arthritis & $3 / 19$ & 15.7 & No & Mean 60.17, & $\mathrm{N} / \mathrm{A}$ & 15.8 & 5.2 \\
\hline Eleftheriou 201510 & UK & $\begin{array}{l}\text { Arthralgia/arthritis } \\
\text { Myalgia }\end{array}$ & $\begin{array}{l}1 / 11 \\
1 / 11\end{array}$ & $\begin{array}{l}9.0 \\
9.0\end{array}$ & $\begin{array}{l}\text { No } \\
\text { No }\end{array}$ & $\begin{array}{l}\text { Median 72, } \\
\text { Range 12-108 }\end{array}$ & $\begin{array}{l}\text { Median 53, } \\
\text { Range 0-237 }\end{array}$ & $\mathrm{N} / \mathrm{A}$ & $\mathrm{N} / \mathrm{A}$ \\
\hline Clemente 201611 & Brazil & Musculoskeletal symptoms & $46 / 71$ & 64.7 & No & Elevated in $80.6 \%$ & N/A & 43.1 & 25 \\
\hline Aeschlimann 201712 & Canada & Back pain & $5 / 27$ & 19 & No & $\begin{array}{l}\text { Elevated in 78\% } \\
\text { Median 35, } \\
\text { IQR 17-74 }\end{array}$ & $\begin{array}{l}\text { Elevated in 80\% } \\
\text { Median 31.9, } \\
\text { IQR 5.3-67.6 }\end{array}$ & $\% \quad \mathrm{~N} / \mathrm{A}$ & 11.1 \\
\hline \multicolumn{10}{|l|}{ Case report } \\
\hline Rossor 19791 & UK & $\begin{array}{l}\text { Limb pain, intermittent } \\
\text { claudication }\end{array}$ & 1 & $\mathrm{~N} / \mathrm{A}$ & Systemic JCA & 97 & N/A & $\mathrm{N} / \mathrm{A}$ & N/A \\
\hline Hall $1986^{2}$ & USA & $\begin{array}{l}\text { Chronic polyarthritis } \\
\text { involving MCPs, PIPs, } \\
\text { wrists, knees, ankles, } \\
\text { cervical spine, TMJ }\end{array}$ & 1 & N/A & Polyarticular JRA & 95 & N/A & $\mathrm{N} / \mathrm{A}$ & $\mathrm{N} / \mathrm{A}$ \\
\hline Our case & Thailand & Chronic arthritis of right knee & 1 & $\mathrm{~N} / \mathrm{A}$ & Oligoarticular JIA & 73 & 48 & Negative & None \\
\hline
\end{tabular}

NA, not-applicable; SD, standard deviation; IQR, interquartile range; ESR, erythrocyte sedimentation rate; CRP, c-reactive protein; JIA, juvenile idiopathic arthritis; JRA, juvenile rheumatoid arthritis; JCA, juvenile chronic arthritis. 
in 3 children with renal manifestations in TA and malignant hypertension, 1 of 3 children had abdominal aortic stenosis with bilateral renal artery stenosis, and renal biopsy revealed arteriolar sclerosis and focal glomerulosclerosis. ${ }^{16}$ FSGS in our case was in the non-stenotic kidney. This was likely secondary to her malignant hypertension and resulted in glomerular hyperfiltration. ${ }^{17}$

\section{Conclusions}

The findings from this case report should heighten awareness and suspicion of TA in children that initially present with chronic monoarthritis mimicking oligoarticular JIA. It must be emphasized that JIA is always a diagnosis of exclusion. Any atypical features of oligoarticular JIA, such as elevated inflammatory marker, frequent disease flares despite receiving appropriate treatment, and hypertension, should illuminate the possibility of an alternative diagnosis including TA. In patients with these manifestations, detailed history taking and thorough physical examination with an emphasis on quality of pulse in all extremities are recommended. Blood pressure surveillance is the important clue for early detection of TA.

\section{References}

1. Rossor E. Takayasu's arteritis as a dif- ferential diagnosis of systemic juvenile chronic arthritis. Arch Dis Child 1979;54:798-800.

2. Hall S, Nelson AM. Takayasu's arteritis and juvenile rheumatoid arthritis. J Rheumatol 1986;13:431-3.

3. Morales E, Pineda C, Martinez-Lavin M. Takayasu's arteritis in children. J Rheumatol 1991;18:1081-4.

4. Hong CY, Yun YS, Choi JY, et al. Takayasu arteritis in Korean children: clinical report of seventy cases. Heart Vessels Suppl 1992;7:91-6.

5. Hahn D, Thomson PD, Kala U, et al. A review of Takayasu's arteritis in children in Gauteng, South Africa. Pediatr Nephrol 1998;12:668-75.

6. Jain S, Sharma N, Singh S, et al. Takayasu arteritis in children and young indians. Int J Cardiol 2000;75:S153-7.

7. Muranjan MN, Bavdekar SB, More V, et al. Study of Takayasu's arteritis in children: clinical profile and management. J Postgrad Med 2000;46:3-8.

8. Fieldston E, Albert D, Finkel T. Hypertension and elevated ESR as diagnostic features of Takayasu arteritis in children. J Clin Rheumatol 2003;9:15663.

9. Cakar N, Yalcinkaya F, Duzova A, et al. Takayasu arteritis in children. J Rheumatol 2008;35:913-9.

10. Eleftheriou D, Varnier G, Dolezalova P, et al. Takayasu arteritis in childhood: retrospective experience from a tertiary referral centre in the United Kingdom. Arthritis Res Ther 2015;17:36.

11. Clemente G, Hilario MO, Len C, et al.
Brazilian multicenter study of 71 patients with juvenile-onset Takayasu's arteritis: clinical and angiographic features. Rev Bras Reumatol Engl Ed 2016;56:145-51.

12. Aeschlimann FA, Eng SWM, Sheikh S, et al. Childhood Takayasu arteritis: disease course and response to therapy. Arthritis Res Ther 2017;19:255.

13. Ozen S, Ruperto N, Dillon MJ, et al. EULAR/PReS endorsed consensus criteria for the classification of childhood vasculitides. Ann Rheum Dis 2006;65: 936-41.

14. Koda R, Yoshino A, Imanishi Y, et al. A case of membranous glomerulonephropathy associated with Takayasu's arteritis. Case Rep Nephrol Urol 2014;4:60-9.

15. Tiryaki O, Buyukhatipoglu H, Onat AM, et al. Takayasu arteritis: association with focal segmental glomerulosclerosis. Clin Rheumatol 2007;26: 609-11.

16. Hijazi R, Chandar J, Nwobi O, et al. Renal manifestations in toddlers with Takayasu's arteritis and malignant hypertension. Pediatr Nephrol 2009;24:1227-30.

17. Bhowmik D, Dash SC, Jain D, et al. Renal artery stenosis and focal segmental glomerulosclerosis in the contralateral kidney. Nephrol Dial Transplant 1998;13:1562-4. 